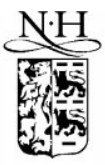

ELSEVIER
Journal of International Economics 49 (1999) 403-412

www.elsevier.nl/locate/econbase

\title{
The gains from duty free zones
}

\author{
Giovanni Facchini, Gerald Willmann* \\ Department of Economics, Stanford University, Stanford, CA 94305-6072, USA
}

Received 18 December 1997; received in revised form 17 August 1998; accepted 26 August 1998

\begin{abstract}
Duty free zones have been established in many countries and duty free shops can be found in every major international airport. This paper investigates their welfare effect, in the tradition of the Pareto gains from trade literature. Using the dual approach developed in Dixit and Norman (1980), we show that the introduction of a duty free zone leads to Pareto gains over autarky. Compared to free trade, its welfare impact depends on the redistribution mechanism accompanying free trade. We show that with a Dixit-Norman tax scheme free trade is Pareto-inferior to a duty free zone regime. The opposite holds true for lump sum redistribution. (C) 1999 Elsevier Science B.V. All rights reserved.
\end{abstract}

Keywords: Pareto gains from trade; Duty free zones

JEL classification: F10; F11

\section{Introduction}

Duty free zones have been established in many countries and duty free shops can be found in every major international airport. Most of us have probably visited one, but not everyone has considered their welfare implications.

Following the establishment of several such zones in developing countries in the late $1960 \mathrm{~s}$ and 70s, economists started analyzing them. To our knowledge, Hamada (1974) is the first important contribution. In it he investigates the impact of duty free zones in the standard Heckscher-Ohlin framework and reaches

\footnotetext{
*Corresponding author. Tel: + 1-650-725-8921; fax: + 1-650-725-5702.

E-mail address: gerald@willmann.stanford.edu. (G. Willmann)
} 
ambiguous conclusions about their welfare effect. This line of research is further pursued by Rodriguez (1976) and Hamilton and Svensson (1982) leading to similar results. Young and Miyagiwa (1987) open a new chapter by taking into account unemployment in a Harris-Todaro-like economy. They conclude that the welfare effect of duty free zones is unambiguously positive. Miyagiwa (1993) extends this analysis focusing on where to locate the duty free zone in a developing country.

Our approach considers a somewhat different notion of duty free zone and stems from a different line of research, the literature on Pareto gains from trade. Kemp and Wan (1972) establish the Pareto superiority of free trade with lump sum redistribution over autarky. Dixit and Norman (1980), aware of the strong informational requirements of this compensation scheme, propose commodity taxation instead and show that their regime Pareto-dominates autarky. Feenstra and Lewis (1991) analyze the effects of free trade with redistribution through nonlinear taxes in a partial equilibrium setting. They point out that a duty free zone can be regarded as a special case of non-linear taxation. Feenstra and Lewis (1994), now in a general equilibrium framework, claim, without providing a proof, the Pareto superiority of a duty free zone over autarky.

This paper provides the formal proof of the above claim for the tractable small country case - the relevant case for most developing countries. In addition we compare the welfare implications of a duty free zone to the situation arising from the above mentioned free trade regimes, i.e. lump sum redistribution or DixitNorman commodity taxation. We establish that duty free zones Pareto-dominate free trade with Dixit-Norman taxes, but in turn are dominated by free trade with lump sum transfers. Subsequently we derive implications from our theoretical analysis for the implementation of duty free zones.

The outline of the paper is as follows. In Section 2 we introduce the formal framework based on the dual approach as presented in Dixit and Norman's seminal book. In Section 3 the Pareto superiority of a duty free zone over autarky is formally established and provides a graphical illustration of the argument. In Section 4 we use the Pareto criterion to rank our duty free zone vis-à-vis the two free trade regimes. In Section 5 concluding remarks and suggestions for further research are offered.

\section{The formal framework}

In this section we set up the formal framework for our analysis. We model explicitly one country vis-à-vis the rest of the world.

First consider the consumption side of this country. Let there be $N$ consumers indexed by $h \in\{1, \ldots, N\}$ and characterized by their excess expenditure functions $e_{h}^{*}(p, w, u)$ which are defined as 


$$
e_{h}^{*}(p, w, u) \equiv \min _{c, v}\left\{p c_{h}-w v_{h} \mid u_{h}\left(c_{h}, v_{h}\right) \geq u\right\}
$$

where $c_{h}$ and $v_{h}$ are, respectively, the consumption and factor supply vectors, $p$ and $w$ the corresponding price vectors, and $u_{h}\left(c_{h}, v_{h}\right)$ their utility functions. The excess expenditure function indicates the minimum lump sum transfer needed to attain the utility level $u$ at given prices $(p, w)$. In what follows we assume that $e^{*}$ has all the usual properties. ${ }^{1}$ Note that we have allowed complete heterogeneity of agents.

On the production side we assume constant returns to scale and price taking profit maximization. Formally this can be described by

$$
\max _{x, v}\{p x-w v \mid(x, v) \text { feasible }\}
$$

where $x$ and $v$ are, respectively, the output and input vectors and $p$ and $w$ the corresponding prices. We think of the rest of the world as being characterized by the vector valued excess demand function $c_{\text {row }}(p)$ which satisfies $p c_{\text {row }}(p)=0$. Putting things together the autarkic equilibrium is defined as a vector of prices $(p$, w) such that

$$
\sum_{h=1}^{N} v_{h}=v \wedge \sum_{h=1}^{N} c_{h}=x
$$

while international equilibrium is defined similarly by replacing the second equation with

$$
\sum_{h=1}^{N} c_{h}+c_{\text {row }}=x
$$

At this point we turn to the main subject of this paper, namely duty free zones. We understand a duty free zone to be an area (not necessarily in the geographical sense), where consumers can trade at international prices after having paid an entrance fee $t \in \mathscr{R}$. It is assumed that, if a consumer is indifferent to entering or staying out, she enters. ${ }^{2}$ Producers are exposed to world market prices and we also assume that it is not possible for goods purchased at international prices in the duty free zone to be resold to outsiders.

Before closing this section let us briefly consider another relevant concept, the commodity tax scheme proposed in Dixit and Norman (1980). The idea is to keep the price vector faced by consumers constant at the autarky level while exposing

\footnotetext{
${ }^{1}$ Cf. Deaton and Muellbauer, (1980, chapter 2) and Dixit and Norman, (1980, also chapter 2).

${ }^{2}$ This is a purely technical assumption that guarantees entry by at least one consumer in the pathological no gains from trade case. It is incentive compatible because the decision to enter or stay out does not affect neither the consumer's nor the government's budget position and therefore will not lead to any change in government policy.
} 
the production side to international prices. This is achieved by means of appropriate excise taxes/subsidies on commodity and factor transactions. It guarantees that consumers will make the same choices as under autarky and therefore attain their autarkic utility levels. In contrast to lump sum transfers the Dixit-Norman tax scheme is incentive compatible.

\section{Pareto gains from duty free zones for a small country}

In this section, we analyze the impact of duty free zones on a small economy, i.e. an economy which takes world prices as given and which does not influence them even passively. Without loss of generality, let individuals be ordered so that $e_{h}^{*}\left(p^{1}, w^{1}, u_{h}{ }^{a}\right)$ is decreasing in $h$, where $p^{1}$ and $w^{1}$ are the world prices for commodities and factor inputs, and $u_{h}{ }^{a}$ is the autarkic utility level of individual $h$. Since $e_{h}^{*}\left(p^{1}, w^{1}, u_{h}{ }^{a}\right)$ can be thought of as the hypothetical transfer needed to keep agents indifferent between autarky and free trade at given world prices, we have ordered them so that individual 1 is the biggest loser while $N$ is the top winner from free trade.

Let us consider the situation in which the government sets up a duty free zone with an entrance fee of $t$. In addition, the production side is exposed to free trade and people who do not enter the duty free zone are kept at their autarkic utility levels by means of Dixit-Norman commodity taxes. We are now able to prove our first result. ${ }^{4}$

Theorem 1. There exists a feasible duty free zone with an entrance fee t, which is frequented by a non-empty subset of the population, and a Dixit-Norman tax scheme for the rest of the economy, which leads to a Pareto improvement over autarky.

Proof: Let $t=-e_{M}^{*}\left(p^{1}, w^{1}, u_{M}{ }^{a}\right)$ for some $M \in\{1, \ldots, N\}$, where $M$ is the marginal agent, i.e. the agent that is indifferent to entering the duty free zone or staying out, and enters by assumption. The number of people $R$ who are willing to enter the duty free zone is then greater or equal ${ }^{5}$ to $N-M$. We are left to show that a marginal agent $M$ and a fee $t$ exist such that this policy is feasible, i.e. that the government budget $B_{D F}$ is non-negative. The government budget can be written as

\footnotetext{
${ }^{3}$ The classic reference on incentive compatibility is Hammond (1979). For a discussion of this specific issue cf. Hammond and Sempere (1995) and for a different perspective cf. Wong (1995).

${ }^{4}$ This result is in the spirit of some trade is better than no trade although here some trade entails non-linear taxation whereas most of the literature considers linear taxes or tariffs.

${ }^{5}$ Strictly greater if there are ties.
} 


$$
\begin{aligned}
B_{D F} & =\left(p^{a}-p^{1}\right) \sum_{h=1}^{N-R} c_{h}^{a}+\left(w^{1}-w^{a}\right) \sum_{h=1}^{N-R} v_{h}^{a}+R t \\
& =w^{1} \sum_{h=1}^{N-R} v_{h}^{a}-p^{1} \sum_{h=1}^{N-R} c_{h}^{a}-\operatorname{Re}_{M}^{*}\left(p^{1}, w^{1}, u_{M}^{a}\right)
\end{aligned}
$$

where the second equality follows from the individual agents' budget constraints in autarky, $p^{a} c_{h}{ }^{a}=w^{a} v_{h}{ }^{a} \forall h \in\{1, \ldots, N\}$. Now, let $M=N$ so that $t=-e_{N}^{*}\left(p^{1}, w^{1}\right.$, $\left.u_{N}{ }^{a}\right)$. It follows that

$$
\begin{aligned}
B_{D F} & =w^{1} \sum_{h=1}^{N-1} v_{h}^{a}-p^{1} \sum_{h=1}^{N-1} c_{h}^{a}-e_{N}^{*}\left(p^{1}, w^{1}, u_{N}^{a}\right) \\
& \geq w^{1} \sum_{h=1}^{N-1} v_{h}^{a}-p^{1} \sum_{h=1}^{N-1} c_{h}^{a}+\left(w^{1} v_{N}^{a}-p^{1} c_{N}^{a}\right) \\
& =w^{1} \sum_{h=1}^{N} v_{h}^{a}-p^{1} \sum_{h=1}^{N} c_{h}^{a}=w^{1} v^{a}-p^{1} x^{a} \\
& \geq w^{1} v^{a}-p^{1} x^{1}=0
\end{aligned}
$$

The second line is implied by the definition of the expenditure function, while the fourth line follows from profit maximization and from the assumption of constant returns to scale.

Remark. We have rigorously shown only that consumer $N$ is indifferent between entering the duty free zone and facing the autarkic price vector, but except for the pathological case of no gains from trade, the tax authorities can lower the fee and thereby increase the number of consumers willing to enter the duty free zone and also enable them to realize gains from trade beyond indifference.

The situation is depicted in Fig. 1. The diagonal line represents the potential gains from free trade for individuals 1 to $N$. Consumers 1 to $M$ decide to stay out of the duty free zone because their potential gains do not exceed the entrance fee. Their utility is kept unchanged with respect to autarky by means of a DixitNorman set of commodity taxes. Individuals to the right of $M$ decide to enter, obtaining gains from trade after paying the entrance fee. The actual welfare gains are depicted by the bold line.

We have argued above that the government should lower the entrance fee. It is intuitive and easy to prove that the government budget decreases with the fee. Let us consider the case of free entry, that is a fee of zero. Only the potential losers will stay outside under the umbrella of the Dixit-Norman tax scheme, but since the government does not collect any revenue from the gainers this policy is feasible only if there are no losers and everyone enters the duty free zone. For similar reasons negative entrance fees are not of interest. 


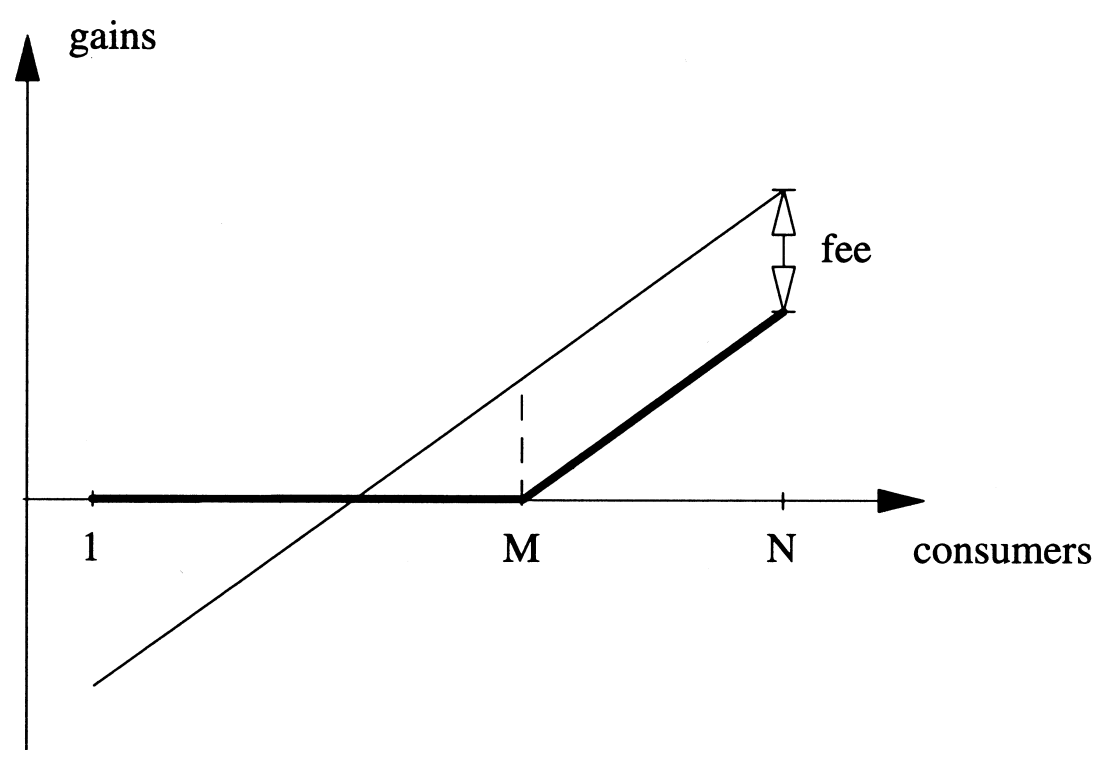

Fig. 1. Gains from trade.

\section{Pareto ranking free trade and duty free zones}

In the previous section we have established the Pareto superiority of duty free zones over autarky. Our objective in what follows is to compare duty free zones to free trade. Obtaining a Pareto ranking requires the use of a redistribution mechanism under free trade. First, let us consider commodity taxation à la Dixit-Norman for every consumer in the economy. Dixit and Norman (1980) have shown that the resulting government budget is non-negative. So, except for the pathological case of no gains from free trade, there will be a budget surplus that can be distributed to consumers by means of lump sum transfers thereby leading to a Pareto improvement over autarky.

Duty free zones can simply be regarded as an alternative way of distributing the surplus to consumers. The fact that those who enter the duty free zone can realize additional gains from substitution on the consumption side is the intuitive argument behind our next result. Without any specific assumption about how the budget surplus is distributed under free trade with Dixit-Norman taxes, it is not possible to obtain a Pareto ranking. Therefore, we consider a lump sum scheme

\footnotetext{
${ }^{6}$ There is an issue here whether this is possible, cf. the exchange between Kemp and Wan (1986) vs. Dixit and Norman (1986), but impossibility to do so would make our alternative look even more attractive.
} 
that aims at reproducing the welfare position of consumers which prevails under the duty free zone.

Theorem 2. Any feasible duty free zone Pareto-dominates free trade with Dixit-Norman commodity taxes where the surplus from the latter scheme is distributed in an attempt to mimic the duty free zone outcome.

Proof. As we have seen in the previous section, the government budget under the duty free zone regime is given by

$$
B_{D F}=\left(p^{a}-p^{1}\right) \sum_{h=1}^{N-R} c_{h}^{a}+\left(w^{1}-w^{a}\right) \sum_{h=1}^{N-R} v_{h}^{a}+R t
$$

Under free trade with a Dixit-Norman tax scheme the budget amounts to

$$
\begin{aligned}
B_{F T D N}= & \left(p^{a}-p^{1}\right) \sum_{h=1}^{N-R} c_{h}^{a}+\left(w^{1}-w^{a}\right) \sum_{h=1}^{N-R} v_{h}^{a}+\left(p^{a}-p^{1}\right) \sum_{h=N-R+1}^{N} c_{h}^{*} \\
& +\left(w^{1}-w^{a}\right) \sum_{h=N-R+1}^{N} v_{h}^{*}-\sum_{h=N-R+1}^{N} e_{h}^{*}\left(p^{a}, w^{a}, u_{h}^{d f}\right)
\end{aligned}
$$

where $c_{h}^{*}$ and $v_{h}^{*}$ are, respectively, the Hicksian consumption and factor supply vectors at autarky prices and duty free zone utility levels $u_{h}^{d f}$. The last term stands for the lump sum transfers to consumers who would otherwise have profited from entering the duty free zone. We want to show that $B_{D F}-B_{F T D N} \geq 0$, i.e. that

$$
\begin{aligned}
R t & -\left(p^{a}-p^{1}\right) \sum_{h=N-R+1}^{N} c_{h}^{*}-\left(w^{1}-w^{a}\right) \sum_{h=N-R+1}^{N} v_{h}^{*} \\
& +\sum_{h=N-R+1}^{N} e_{h}^{*}\left(p^{a}, w^{a}, u_{h}^{d f}\right) \geq 0
\end{aligned}
$$

Since $p^{a} c_{h}^{*}-w^{a} v_{h}^{*}=e_{h}^{*}\left(p^{a}, w^{a}, u_{h}^{d f}\right) \forall h \in\{N-R+1, \ldots, N\}$, this is the case if

$$
R t+p^{1} \sum_{h=N-R+1}^{N} c_{h}^{*}-w^{1} \sum_{h=N-R+1}^{N} v_{h}^{*} \geq 0
$$

By definition of the expenditure function $p^{1} c_{h}^{*}-w^{1} v_{h}^{*} \geq e_{h}^{*}\left(p^{1}, w^{1}, u_{h}{ }^{d f}\right) \forall h \in$ $\{N-R+1, \ldots, N\}$. Therefore we have

$$
R t+p^{1} \sum_{h=N-R+1}^{N} c_{h}^{*}-w^{1} \sum_{h=N-R+1}^{N} v_{h}^{*} \geq R t+\sum_{h=N-R+1}^{N} e_{h}^{*}\left(p^{1}, w^{1}, u_{h}^{d f}\right)=0
$$

where the last equality follows from $e_{h}^{*}\left(p^{1}, w^{1}, u_{h}{ }^{d f}\right)=-t \forall h \in\{N-R+1, \ldots$, $N\}$.

Note that this result holds a fortiori if the Dixit-Norman surplus is simply disposed of. 
Let us now consider the case of free trade with lump sum redistribution. The following result is included to complete the ordering and does not come as a surprise given the first best nature of free trade with lump sum transfers.

Theorem 3. There exists a lump sum redistribution scheme such that free trade Pareto-dominates any feasible duty free zone.

Proof. Let the lump sum scheme be such that consumers who did not enter the duty free zone are kept at their autarkic utility levels while the former entrants still have to surrender $t$ as a lump sum payment. Then

$$
B_{F T L S}=-\sum_{h=1}^{N-R} e_{h}^{*}\left(p^{1}, w^{1}, u_{h}^{a}\right)+R t \geq w^{1} \sum_{h=1}^{N-R} v_{h}^{a}-p^{1} \sum_{h=1}^{N-R} c_{h}^{a}+R t=B_{D F}
$$

by definition of the expenditure function. $\square$

The results are summarized in Fig. 2. Free trade with appropriate lump sum redistribution Pareto-dominates any feasible duty free zone, which is Paretosuperior to free trade with a Dixit-Norman tax scheme. This last regime in turn dominates autarky, establishing the ordering depicted in Fig. 2.

When evaluating these results, it is important to note the different informational requirements. Free trade with lump sum transfers presupposes that the government knows the welfare position of each single agent before and after liberalization. It was this unrealistically strong assumption of omniscience which led Dixit and Norman to propose their commodity tax scheme. Here we have shown that one can improve upon their scheme without any additional information by establishing a duty free zone. Note, however, that all the arguments raised against the DixitNorman $^{7}$ tax scheme also apply to our duty free zone, because we used such taxes to warrant the autarkic utility levels of outsiders. Furthermore, there is no reason to believe that duty free zones are the optimal form of redistribution through non-linear taxation.

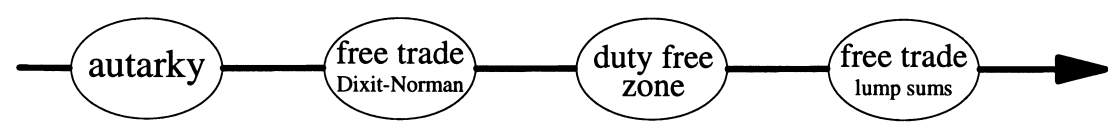

Fig. 2. Pareto ranking.

\footnotetext{
${ }^{7}$ Implementation of this tax scheme requires bureaucrats to freeze prices through carefully chosen taxes. This will not only be extremely demanding in terms of information and resources, but different tax rates invite rent seeking. In addition, it is hard to imagine how different production and consumption prices can be enforced for production units, such as farms, who also consume part of their output. Finally, if we take the assumption of constant returns to scale to stand for decreasing returns plus specific entrepreneurial factors, different tax rates for these factors imply varying tax rates for pure profits, which is impossible even conceptually.
} 


\section{Concluding remarks}

The concept of duty free zone analyzed above differs from real world examples on two counts: In our conceptualization we assume the production side of the economy to be completely exposed to international competition, while in the real world this is only the case for businesses located within the limited area of the duty free zone. Second, we use Dixit-Norman commodity taxation for people staying outside the zone, which is somewhat unrealistic (cf. footnote 7), although it has a distant counterpart in redistributive tax policies. On the other hand note that we obtain an ordering according to the Pareto criterion, an extremely strong comparative result. The political decision process will usually settle for less than such a strong ordering, thus allowing us some leeway when it comes to interpreting the requirements necessary for our results. Nevertheless it is worth emphasizing that the contribution of this paper is mainly theoretical. We show that our notion of a duty free zone Pareto-dominates free trade with a Dixit-Norman tax scheme and we improve upon that regime without any additional informational requirements. This analysis has been fully developed for the static small country case. The extension to the more general large country setting poses some technical difficulties: The price vector prevailing on international markets (and therefore also in the duty free zone) is now endogeneously determined by the make-up of the zone itself. In addition, the ordering of consumers according to their potential gains from trade will depend on world prices. Proving similar results for this case is left for further research as is the extension to a dynamic setting.

\section{Acknowledgements}

The authors would like to thank Peter Hammond for useful suggestions. Facchini gratefully acknowledges financial support provided by the Fondazione Caritro through the A. Brunazzo fellowship.

\section{References}

Deaton, A., Meullbauer, J., 1980. Economics and Consumer Behavior. Cambridge University Press, Cambridge.

Dixit, A., Norman, V., 1986. Gains from trade without lump-sum compensation. Journal of International Economics 21, 111-122.

Dixit, A.K., Norman, V., 1980. Theory of International Trade. Cambridge University Press, Cambridge.

Feenstra, R.C., Lewis, T.R., 1991. Distributing the gains from trade without lump-sum compensation. Economics and Politics 3, 21-40.

Feenstra, R.C., Lewis, T.R., 1994. Trade adjustment assistance and Pareto gains from trade. Journal of International Economics 36, 201-222. 
Hamada, K., 1974. An economic analysis of the duty-free zone. Journal of International Economics 4, $225-241$.

Hamilton, C., Svensson, L.E., 1982. On the welfare effects of a 'duty-free zone'. Journal of International Economics 13, 45-64.

Hammond, P.J., 1979. Straightforward individual inceptive compatibility in large economies. Review of Economic Studies 46, 263-282.

Hammond, P.J., Sempere, J., 1995. Limits to the potential gains from economic integration and other supply side policies. Economic Journal 105, 1180-1204.

Kemp, M.C., Wan, H.Y., 1972. The gains from free trade. International Economic Review 13, 509-522.

Kemp, M.C., Wan, H.Y., 1986. Gains from trade with and without lump-sum compensation. Journal of International Economics 21, 99-110.

Miyagiwa, K.F., 1993. The locational choice for free-trade zones: Rural versus urban options. Journal of Development Economics 40, 187-203.

Rodriguez, C.A., 1976. A note on the economics of the duty free zone. Journal of International Economics 6, 385-388.

Wong, K., 1995. International Trade in Goods and Factor Mobility. MIT Press, Cambridge, MA, London.

Young, L., Miyagiwa, K.F., 1987. Unemployment and the formation of duty-free zones. Journal of Development Economics 26, 397-405. 